\title{
Research Paper: Mediation Role of Psychological Capital Between Job Stress, Burnout, and Mental Health Among Nurses
}

\author{
Hadi Asheghi ${ }^{1}$ (D), Mostafa Asheghi ${ }^{2}$, Mohsen Hesari $^{3^{*}}$ (i)
}

1. Health Economics, Faculty of Public Health, Tehran University of Medical Sciences, Tehran, Iran

2. Industrial \& Organizational Psychology, Faculty of Education \& Psychology, Shahid Chamran University of Ahvaz, Ahvaz, Iran.

3. Department of Clinical Psychology, Faculty of Medicine, Shahid Beheshti University of Medical Sciences, Tehran, Iran.

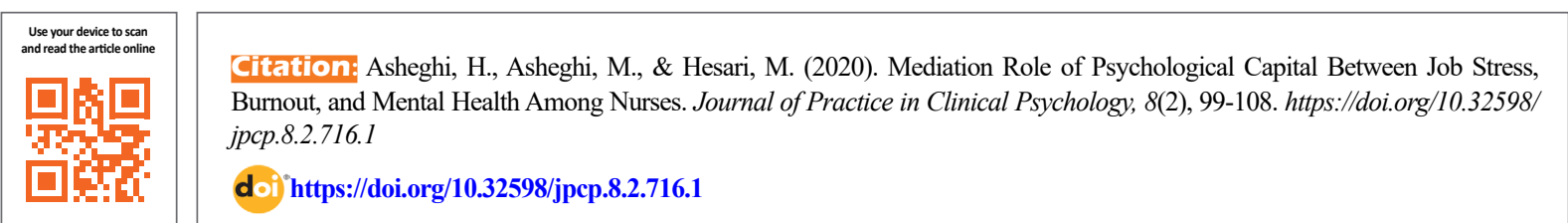

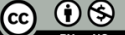

Article info:

Received: 13 Dec 2019

Accepted: 25 Feb 2020

Available Online: 01 Apr 2020

Keywords:

Job stress, Psychological capital, Job burnout, Mental health

\section{ABSTRACT}

Objective: Mental health, job burnout, and job stress have an important role in the wellbeing of nurses and their services. The present study aimed to investigate the relationship between job stress and burnout and mental health with the mediation of psychological capital.

Methods: The participants included 250 nurses from Bojnourd City, Iran who were selected by the available sampling method. The data were analyzed by Structural Equation Modeling (SEM) in SPSS version 23 and AMOS version 24.

Results: Structural equation modeling analysis confirmed the proposed pattern. The results showed the direct effect of job and indirect effect of stress through psychological capital on the mental health and burnout.

Conclusion: According to the results, hospitals and medical centers can benefit from psychological capital and its components to reduce job stress and burnout, and to increase mental health.

\section{* Corresponding Author:}

Mohsen Hesari, MSC.

Address: Department of Clinical Psychology, Faculty of Medicine, Shahid Beheshti University of Medical Sciences, Tehran, Iran.

Tel: +98 (935) 3869094

E-mail: mohsenhesari72@yahoo.com 


\section{Highlights}

- There is a negative relationship between job stress and burnout with psychological capital.

- Psychological capital as a positive personal resource can play a significant role in fighting nurses' job stress.

\section{Plain Language Summary}

Job burnout is the result of long-term job stress that is not recognized and addressed until it gets out of control. It involves mental, emotional, or physical exhaustion, frequently accompanied by an overwhelming sense of hopelessness. Nursing burnout is a widespread phenomenon characterized by a reduction in nurses' energy that manifests itself in emotional exhaustion, lack of motivation, and feelings of frustration and may lead to reductions in work efficiency. Psychological capital is one of the components of positive psychology, which includes characteristics such as a person's belief in his ability to succeed, perseverance in pursuing goals, a positive view of themselves, and resilience in fighting problems. Psychological capital enables nurses to have more resistance against stressful events, to be less stressed, to be more able to cope with problems, to have a more realistic view of themselves, and to be less affected by daily events. As a result, we can see the role and importance of psychological capital and individual attitudes in the development and prevention of burnout.Because the main task of nursing is human care, if nurses have the physical health and psychological capital, they can better manage the stress associated with their job and cope with their heavy and important duties.

\section{Introduction}

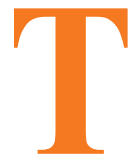

he World Health Organization defines workplace stress as a disease that causes serious health problems and negative working behaviors. Term "stress" was first used by Selye (1976) and is defined as the body's non-specific response to any demand for change (Aydin, 2004). Job stress, also known as workplace stress, is a global problem that arises in a highly stressful work environment. Health care workers can often be exposed to problems caused by job stress (Gulavani \& Shinde, 2014). Stress is a natural and integral part of everyday life. While it can cause widespread anxiety, there is also an effective coping mechanism to control and reduce its effects (Yoshizawa et al., 2016). Because of the significant negative relationship between job stress and mental health (Sugawara et al., 2017), paying attention to and controlling job stress in the workplace can increase mental health and reduce job burnout.

Job burnout is a stress syndrome that is caused by chronic stress in the workplace and includes three components: emotional fatigue, identity loss, and decreased personal adequacy (Lizano \& Barak, 2015).

These pressures and stresses can affect a person's mental health (Greenberg, Docherty, Gnanapragasam \& Wessely, 2020). According to reports in our country, the prevalence of occupational burnout in nurses is so high that in hospitals affiliated to Babol University of Medical Sciences, $68 \%$ of nurses report burnout. The most common causes of burnout in this study are low salaries and benefits, lack of managers' support, lack of job security, and long working hours (Aziz Nejad \& Hosseini, 2006). This phenomenon is the cause of reduced job performance and increased risk of cardiovascular disease (Toker, Melamed, Berliner, Zeltser, \& Shapira, 2012) and increased symptoms of depression and decreased satisfaction with life (Thuynsma \& De Beer, 2017).

A growing body of literature has documented the pervasiveness of job stress and burnout among physicians and other medical personnel. These groups include physicians in primary care, internal medicine, and family medicine; physician assistants; nurses; medical residents; and many others (Kelly, Soles, Garcia, \& Kundu, 2020).

According to the World Health Organization, nurses are the backbone of the health care system in all societies (Krasikova, Lester, \& Harms, 2015), which shows the importance of paying special attention to nurses and their health in all societies. Nursing is one of the most challenging professions due to the emotional nature of the patient's desires, long and professional working hours, as well as interpersonal conflicts. In recent years, new healthcare technologies, budget cuts, and changing healthcare conditions have increased personal and occupational stress among nurses (Jennings, 2008; Khamisa, Peltzer, Ilic, \& Oldenburg, 2017). 
Psychological capital is considered an undeniable resource in coping with stress (Avey, Luthans, Smith, \& Palmer, 2010; Bandura, 1997; Masten \& Reed, 2002; Seligman 1998). Psychological capital is a cohesive structure that includes the four perceptual-cognitive components of hope, optimism, self-efficacy, and resilience (Story, Youssef, Luthans, Barbuto, \& Bovaird 2013). These four independent dimensions by Luthans, Youssef, and Avolio (2007) are defined as follows: having the confidence to overcome challenges (selfefficacy), having a positive attitude and expectations for success now or in the future (optimism), having perseverance towards success and revision options (hope), being able to deal with problems, and keep moving forward (resilience).

One of the most important criteria for psychological capital is flexibility and the ability to change and increase it. Longitudinal studies have confirmed that psychological capital changes over time (Avey et al., 2010; Peterson \& Zhang, 2011). Psychological studies also supported the view that psychological capital increases due to short-term interventions and exercises. As the impact of psychological capital on employee performance and corporate competitiveness has been identified, the number of studies on psychological capital increased (Çelik, 2018). Psychological capital, as a personal resource with positive dimensions within itself (self-efficacy, hope, resilience, and optimism) confronts negative consequences such as stress, burnout, work-family conflict in the workplace (Kan \& Yu, 2016; Matoori, 2017). Hope is one of the four main components of psychological capital that helps a person stay optimistic. And this optimism enables one to endure risk and succeed in an innovative process and tolerate negative external conditions (Tang, 2020).

Research has shown a negative relationship between psychological capital and job stress (Rabenu, Yaniv, \& Elizur, 2017). People with higher psychological capital reported lower levels of job stress than those with lower psychological capital (Abbas \& Raja, 2015). Psychological capital helps increase people's resilience thresholds to bring their coping skills to stress and is seen as an important factor in this regard (Çelik, 2018). Research on the relationship between psychological capital and mental health has shown that the development of psychological capital components such as hope, resilience, self-efficacy, and optimism is significantly associated with increased mental health. Improving psychological capital can lead to psychological wellbeing (Avey et al., 2010; Culbertson, Fullagar, \& Mills, 2010; Krasikova, Lester, \& Harms, 2015; Selvaraj \& Bhat, 2018) show that soldiers with high levels of psychological capital before deployment are less likely to be diagnosed with mental health problems and post-deployment drug use. Decreased levels of psychological capital are associated with increased mental health problems such as post-traumatic stress disorder, anxiety, depression, and drug use. On the other hand, evidence suggests a negative relationship between psychological capital and factors such as stress, anxiety, behavioral distress, and job burnout at work (Krasikova, Lester, \& Harms, 2015).

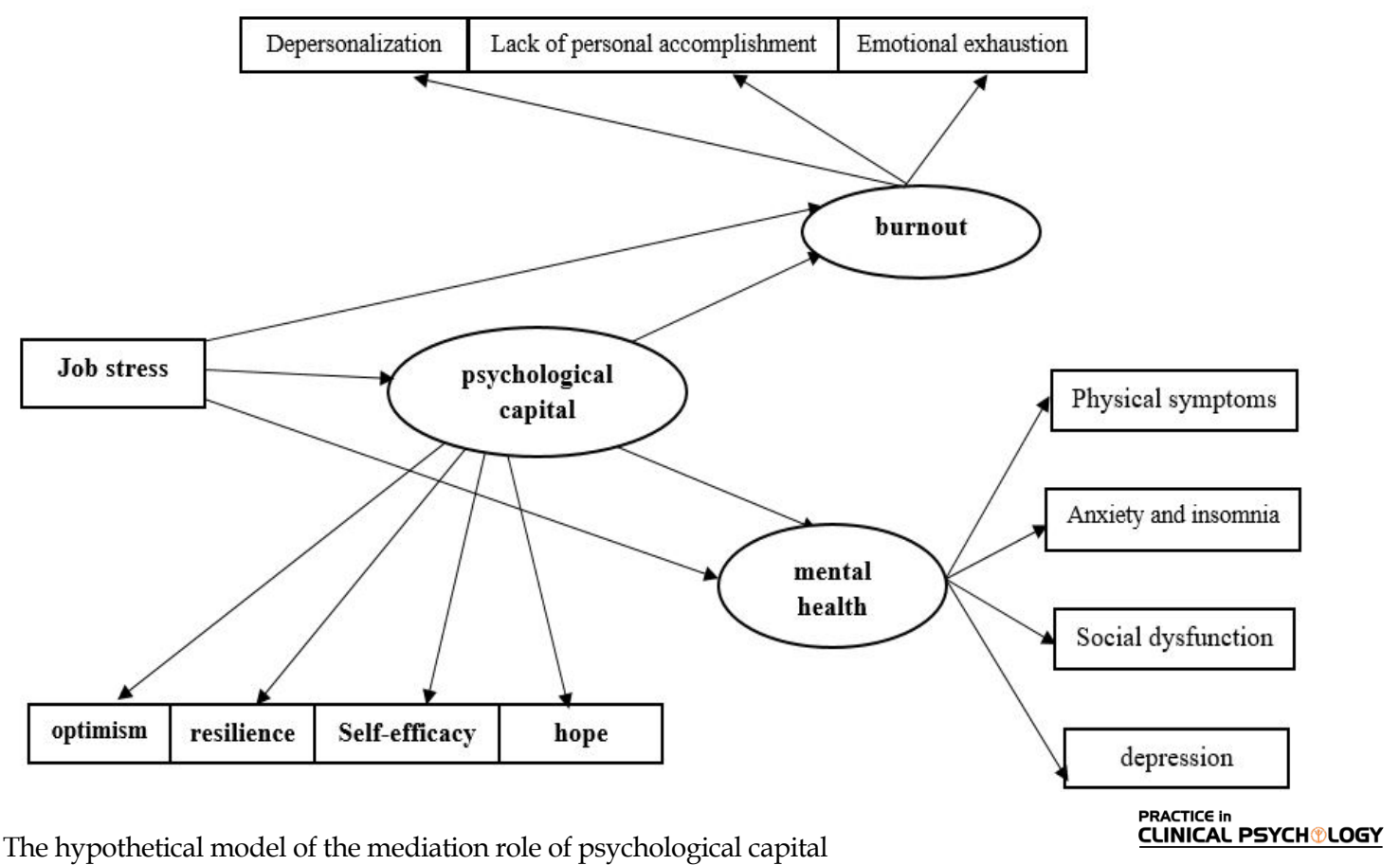

Figure 1. The hypothetical model of the mediation role of psychological capital 
For the research background on the relationship between job burnout and psychological capital, studies done by some researchers (Hansen, Buitendach, \& Kanengoni, 2015; Leon-Perez, Antino, \& Leon-Rubio, 2016; Li et al., 2015; Peng et al., 2013) can be noted. Nezami and Givarian (2016) also found that the components of psychological capital affect nurses' burnout. Nurses with psychological capital, positive characteristics such as self-efficacy and self-confidence in performing their professional duties, high hopes and optimism for their future careers and resilience and flexibility in facing job problems are less likely to suffer from burnout compared to people who lack these features. Research has also been done on the mediating role of psychological capital between job stress and job satisfaction and burnout among Bank of China employees (Li et al., 2015) and the mediating role of psychological capital between job stress and job abandonment among nurses (Yim, Seo, Cho, \& Kim, 2017; Wang, Liu, Yu, Wu, Chang, \& Wang, 2017) Because of the relationship between psychological capital with variables such as burnout, job stress, and mental health, paying attention to it among nurses have an important and vital role in the health of nurses. Therefore, according to the research background mentioned, the present study examined the relationship between job stress with burnout and mental health with the mediation of psychological capital which was examined in the form of a model in Figure 1.

\section{Methods}

\section{Study participants}

The statistical population of the present study includes all nurses working in Bojnourd City in 2019. Of them, 250 were selected using the available sampling method to study the proposed model. The sample size of this study was determined based on the number of parameters. Considering Klein's (1988) suggestion, at least 10 subjects are required for each calculated parameter to test the model (Hashemi, Savadkouhi, Naami, \& Beshlideh, 2018). In this study, 31 parameters were calculated based on the number of direct routes (16 routes), the number of extrinsic variables (1 variable), and the number of error variance (14 errors). According to the sample size of the present study, about 8 subjects were considered for each parameter, which indicates the adequacy of the sample to test the model.

\section{Study procedure}

Given that the purpose of this study was to investigate the relationship between job stress with burnout and men- tal health with the mediation of psychological capital, the design of the research was cross-sectional (Gall, Borg, $\&$ Gall, 2006). Regarding the ethical consideration, the researcher provided the necessary explanations about the study objectives. Then, the researcher proposed the instructions for filling the questionnaires and finally, asked them to participate in the research. Data collection tools were psychological capital questionnaires (Luthans, Youssef \& Avolio, 2007), job stress questionnaire (Jamal \& Baba, 1992), Maslach job burnout questionnaire (1981), and psychological health questionnaire (Goldberg, 1979). A total of 275 questionnaires were distributed that after collecting the questionnaires by eliminating 15 incomplete or confused questionnaires, the number of samples was reduced to 250 participants (67 men and 183 women). The data were analyzed by Structural Equation Modeling (SEM) in SPSS version 23 and AMOS version 24.

\section{Study questionnaires:}

\section{Job Stress Questionnaire}

In this study, the 9-item job stress questionnaire of Jamal and Baba (1992) was used to measure job stress. The answers to this questionnaire are rated on a 5-point Likert-type scale from 1 (strongly opposed) to 5 (strongly agree). The authors report that the reliability coefficient of this questionnaire is 0.83 by calculating the Cronbach alpha (Jamal \& Baba, 1992). In the present study, the Cronbach alpha method was used to calculate the reliability coefficient, which was 0.79 , indicating the acceptable reliability of this questionnaire.

\section{Job Burnout Questionnaire}

Job burnout questionnaire (Maslach \& Jackson, 1981), includes 22 items, nine of which are related to emotional exhaustion, eight to the lack of personal accomplishment, and five to depersonalization. These 22 items are rated from never (0) to very high (6). The minimum and maximum scores in this questionnaire are 0 and 132, respectively (Maslach \& Jackson, 1981). Using the Cronbach alpha, the calculated internal consistency of this questionnaire was 0.83 (Maslach, Jackson, \& Leiter, 1996). This questionnaire was validated and used by Filian (1992) in Iran and its reliability coefficient was found to be 0.78 using the test-retest method. In the present study, the Cronbach alpha method was used to calculate the reliability coefficient of the burnout questionnaire and its components. And the reliability coefficient of 0.84 was obtained for the whole questionnaire. The reliability coefficients were obtained as $0.78,0.83$, and 0.88 for emotional exhaustion, lack of personal accomplish- 
ment, and depersonalization, respectively, which indicates the acceptable reliability coefficient of this questionnaire.

\section{Mental Health Questionnaire}

In the present study, Goldberg and Hillier's general health questionnaire (1979) was used to assess mental health. it consists of 28 items that respondents rate them on a 4-point Likert-type scale (from better than usual $=0$ to much less than normal=3). The questionnaire consists of four subscales. Items 1 to 7 are related to the subscale of physical symptoms, items 8 to 14 to the subscale of anxiety and insomnia, items 15 to 21 to the subscale of social dysfunction, and items 22 to 28 to the subscale of depression. In a study, the reliability of this questionnaire and its subscales were found $0.92,0.71,0.80,0.93$, and 0.87 , respectively by calculating the Cronbach alpha (Mehrabizadeh Honarmand, Atashafrouz, Shehni Yiylagh, \& Rezaie, 2014). In the present study, the Cronbach alpha method was used to calculate the reliability coefficient of the mental health questionnaire and its components. The reliability coefficient was 0.83 for the whole questionnaire and $0.73,0.82,0.84$ and 0.88 were obtained for social symptoms, anxiety and insomnia, social dysfunction and depression, respectively, which indicate the acceptable coefficient of this questionnaire.

\section{Psychological Capital Questionnaire}

The psychological capital questionnaire was designed by Luthans in 2007 and includes 24 items and 4 subscales of self-efficacy, hope, optimism, and resilience. Each subscale contains 6 items, and the respondent responds to each item on a 6-point scale. To acquire the psychological capital score, first, the score of each subscale is obtained separately, and then their sum is considered as the total score of the psychological capital (Luthans \& Youssef, 2007). In the study, by analyzing the confirmatory factors, the proportional fitness index $\left(\chi^{2} / \mathrm{df}=2.31\right)$, the incremental fit index $(\mathrm{IFI}=0.90)$ and the Confirmatory Fit Index $(\mathrm{CFI}=0.90)$ and the Root Mean Of Approximation Error Averages (RM$\mathrm{SEA}=0.06$ ) were obtained which indicate the suitability of the model and the validity of the questionnaire. Also, the Cronbach alpha coefficient for this questionnaire was 0.85 , which shows the reliability of this tool (Hashemi, Savadkouhi, Naami, \& Beshlideh, 2018). The reliability coefficient of this questionnaire in the present study was calculated as 0.76 using the Cronbach alpha method. Also, the Cronbach alpha coefficients for self-efficacy, hope, resilience, and optimism were obtained as $0.72,0.81,0.68$, and 0.76 respectively. This, of course, shows the reliability of this questionnaire.

\section{Results}

The conceptual model of Figure 1 was analyzed using the structural equation modeling in AMOS-24 statistical software. To measure fitness, the proposed model of a combination of fitness measures such as relative Chisquare $\left(\chi^{2} / \mathrm{df}\right)$, Incremental Fitness Index (IFI), Confirmatory Fit Index (CFI), Good Fitness Index (GFI), Adjusted Good Fitness Index (AGFI), Toker-Lewis Index (TLI), and Bentler-Bont index or Normed Fit Index (NFI) were used.

The Mean \pm SD age of the participants was $34.52 \pm 8.36$ years, also $73.28 \%$ of the subjects were female and $72.52 \%$ were married.

Means, standard deviations, and bivariate correlations among the variables are presented in Table 1 . As can be noted, all the correlations between variables were significant at $\mathrm{P}<0.01$. Fit indices for the proposed and final models are presented in Table 2 . The proposed model was tested through structural equation modeling. Fit indices show that the proposed model is fitted with data.

Bootstrapping procedures were used to test the mediation paths. We generated 5000 bootstrapping samples from the original dataset $(\mathrm{N}=250)$. Table 3 presents the direct effects and Table 4 the indirect effects and their associated $95 \%$ confidence intervals. As presented in Table 4 , job stress has a significant indirect effect on burnout and mental health through psychological capital. Figure 2 presents the final model and standardized regression weights.

\section{Discussion}

This study aimed to investigate the mediating role of psychological capital in the relationship between job stress and burnout and mental health. The results generally showed a negative relationship between job stress with psychological capital ( $\mathrm{P}=0.001, \beta=0.39)$ and mental health $(\mathrm{P}=0.002$, $\beta=0.28$ ) and a positive relationship with burnout $(\mathrm{P}=0.01$, $\beta=0.25$ ). Also, there is a negative relationship between psychological capital with burnout $(\beta=0.33, \mathrm{P}=0.001)$ and a positive relationship with mental health $(\beta=0.22$, $\mathrm{P}=0.002$ ). The results also showed the mediating role of psychological capital in the relationship between job stress and burnout and the mental health of nurses.

In the present study, the results showed a positive and significant relationship between job stress and burnout. Nurses with a high level of workload and high energy expenditure to perform their tasks have less time for 
Table 1. Descriptive statistics and bivariate correlations among the variables

\begin{tabular}{|c|c|c|c|c|c|c|c|c|}
\hline & Variables & Mean $\pm S D$ & 1 & 2 & 3 & 4 & 5 & 6 \\
\hline 1 & Job Stress & $28.42 \pm 6.78$ & - & & & & & \\
\hline 2 & Psychological Capital & $79.18 \pm 11.17$ & $-0.48 *$ & - & & & & \\
\hline 3 & Burnout & $65.24 \pm 9.11$ & $0.079 *$ & $-0.41^{*}$ & - & & & \\
\hline 4 & Mental Health & $66.46 \pm 10.67$ & $-0.69 *$ & $0.57^{*}$ & $-0.66^{*}$ & - & & \\
\hline
\end{tabular}

Table 2. Fit indices among competing models

\begin{tabular}{lcccccccccc}
\hline $\begin{array}{c}\text { Variable Fit } \\
\text { Indices }\end{array}$ & $\mathbf{x}^{2}$ & $\mathbf{d f}$ & $\mathbf{x}^{2} / \mathbf{d f}$ & GFI & AGFI & NFI & CFL & IFI & TLI & RMSEA \\
\hline Acceptable values & - & - & $<5$ & $\geq 0.90$ & $\geq 0.90$ & $\geq 0.90$ & $\geq 0.90$ & $\geq 0.90$ & $\geq 0.90$ & $\leq 0.080$ \\
Proposed model & 108.434 & 50 & 2.16 & 0.95 & 0.94 & 0.93 & 0.94 & 0.94 & 0.93 & 0.05 \\
\hline
\end{tabular}

PRACTICE In
CLINICAL PSYCH LOGY

N: 250; RMSEA: Root Mean Square Error of Approximation; CFI: Comparative Fit Index; IFI: Incremental Fit Index; NFI: Normed Fit Index

competitive pressures and changing hospital procedures and policies. This condition increases the stress and psychological stress on nurses, which leads to a decrease in mental health (Sugawara et al., 2017) and an increase in burnout (Khamisa et al., 2017). Therefore, measures should be taken to control this stress in the workplace. One of the factors that can be helpful in this regard is the promotion of psychological capital among individu- als. Psychological capital as a positive personal resource can play a significant role in fighting nurses' job stress (Abbas \& Raja, 2015; Kan \& Yu, 2016; Matoori, 2017; Rabenu, Yaniv, \& Elizur, 2017). Psychological capital is also an effective source for reducing stress, burnout, and depression (Peng et al., 2013; Hansen, Buitendach, \& Kanengoni, 2015; Krasikova, Lester, \& Harms, 2015; Leon-Perez, Antino, \& Leon-Rubio, 2016; Li et al.,

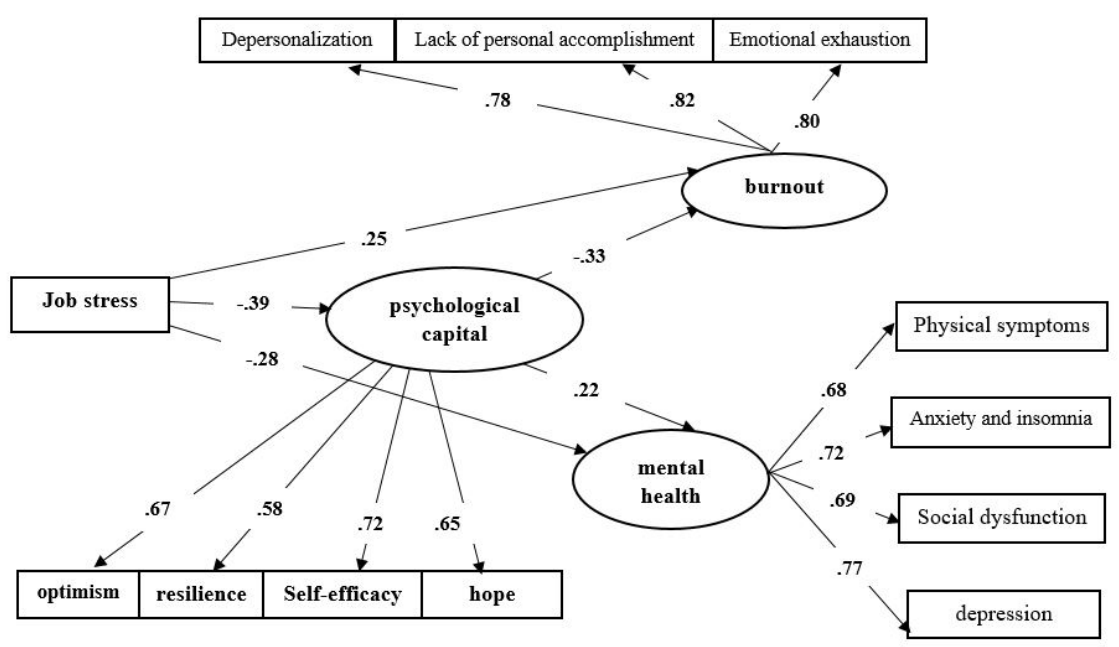

Figure 2. Standardized regression weights for the final model paths 
Table 3. Direct effects for the final mediational model

\begin{tabular}{cccccc}
\hline Paths & $\begin{array}{c}\text { Standard } \\
\text { Estimates }\end{array}$ & $\begin{array}{c}\text { Non-standard } \\
\text { Estimation }\end{array}$ & SE & CR & P \\
\hline Job Stress $\rightarrow$ Burnout & 0.25 & 0.18 & 0.08 & 2.94 & 0.01 \\
\hline Job Stress $\rightarrow$ Mental health & -0.28 & -0.32 & 0.25 & -3.48 & 0.002 \\
\hline Job Stress $\rightarrow$ Psychological capital & -0.39 & -0.45 & 0.04 & -5.63 & 0.001 \\
\hline Psychological capital $\rightarrow$ burnout & -0.33 & -0.25 & 0.02 & -4.14 & 0.001 \\
\hline Psychological capital $\rightarrow$ Mental Health & 0.22 & 0.14 & 0.09 & 2.63 & 0.002 \\
\hline
\end{tabular}

Table 4. Indirect effects for the final mediational model using Bootstrapping

\begin{tabular}{|c|c|c|c|c|}
\hline \multirow{2}{*}{ Indirect Paths } & \multirow{2}{*}{$\begin{array}{l}\text { Indirect } \\
\text { Effect }\end{array}$} & \multicolumn{2}{|c|}{$\begin{array}{l}\text { 95\% Confidence } \\
\text { Interval }\end{array}$} & \multirow{2}{*}{$\mathbf{P}$} \\
\hline & & Lower & Upper & \\
\hline Job stress $\rightarrow$ Psychological capital $\rightarrow$ Burnout & 0.1521 & 0.0672 & 0.2202 & 0.001 \\
\hline Job stress $\rightarrow$ Psychological capital $\rightarrow$ Mental health & 0.2232 & 0.1009 & 0.3217 & 0.001 \\
\hline
\end{tabular}

2015), and increase in mental health (Wang, Liu et al., 2017). Therefore, nurses with sufficient psychological capital, with self-efficacy in performing tasks, as well as more optimism and hope for success in their profession, show high resilience and flexibility in the face of stressful issues and problems in the workplace. And it makes them feel less tired and makes their job burnout relieved and their mental health increased. Therefore, psychological capital is an important source of fighting job burnout and increasing mental health.

\section{Conclusion}

Hospital and medical center management can build trust with nurses by increasing effective communication and establishing fair and impartial systems in the workplace that result in the reduction of job stress in the workplace. Also, paying attention to psychological capital can significantly overcome job stress and burnout and increase the mental health of nurses.

\section{Study limitations}

First, this study was conducted in a cross-sectional way, and we know that longitudinal studies provide a better understanding of the matter at hand. Second, future researchers at other health centers are also advised to repeat this study. Comparing the findings of this study with other findings in other health centers can lead to a better understanding of psychological capital in nursing workplaces. It is recommended that future research consider other individual, professional, and organizational outcomes such as job satisfaction, organizational commitment, work-family conflict, and so on. In addition to these self-report questionnaires, it is also suggested that other methods such as field observations and studies be used to measure the variables of this research.

\section{Ethical Considerations}

\section{Compliance with ethical guidelines}

All ethical principles were observed in this article. The participants were informed about the purpose of the research and its implementation stages. They were also assured about the confidentiality of their information. Moreover, they were allowed to leave the study whenever they wanted, and if desired, the results of the research would be available to them.

\section{Funding}

This research did not receive any specific grant from funding agencies in the public, commercial, or not-forprofit sectors. 


\section{Authors' contributions}

All authors contributed equally in preparing all parts of the research.

\section{Conflict of interest}

The authors declared no conflict of interest.

\section{References}

Abbas, M., \& Raja, U. (2015). Impact of psychological capital on innovative performance and job stress. Canadian Journal of Administrative Sciences, 32(2), 128-38. [DOI:10.1002/cjas.1314]

Avey, J. B., Luthans, F., Smith, R. M., \& Palmer, N. F. (2010). Impact of positive psychological capital on employee well-being over time. Journal of Occupational Health Psychology, 15(1), 17-28. [DOI:10.1037/a0016998] [PMID]

Aydın, Ş. (2004). “Organizational stress management". Dokuz Eylul University Journal of Graduate School of Social Sciences, 6(3) 49-74.

Aziz Nejad, P., \& Hosseini, S. J. (2006). [Occupational burnout and its causes among practicing nurses in hospitals affiliated to Babol University of Medical Sciences, 2004 (Persian)]. Journal of Babol University of Medical Sciences, 8(2), 63-9. http://jbums. org/article-1-2561-en.html

Bandura, A. (1997). Theoretical perspectives. Self-efficacy: The exercise of control, 1-35.

Celik, M. (2018). The effect of psychological capital level of employees on workplace stress and employee turnover intention Innovar, 28(68), 67-75. [DOI:10.15446/innovar.v28n68.70472]

Culbertson, S. S., Fullagar, C. J., \& Mills, M. J. (2010). Feeling good and doing great: The relationship between psychological capital and well-being. Journal of Occupational Health Psychology, 15(4), 421-33. [DOI:10.1037/a0020720] [PMID]

Filian, E. (1992). Relationship between level of burnout and coping strategies in nurses. Tehran: Tarbiat Modares University.

Gall, M. D., Borg, W. R., \& Gall, J. P. (2006). Educational research: An introduction [A. R. Nasr, M. Abolghasemi, K. H. Bagheri, M. J. Pakseresht, Z. Khosravi, \& M. Shahani Yeilagh, Persian Trans]. $2^{\text {nd }}$ Ed. Tehran: SAMT. http://opac.nlai.ir/opac-prod/ bibliographic/685798

Greenberg, N., Docherty, M., Gnanapragasam, S., \& Wessely, S. (2020). Managing mental health challenges faced by healthcare workers during covid-19 pandemic. BMI, 368, m1211. [DOI:10.1136/bmj.m1211] [PMID]

Gulavani, A., \& Shinde, M. (2014). Occupational stress and job satisfaction among nurses. International Journal of Science and Research, 3(4), 733-40. https://www.hrhresourcecenter.org/ node/5621.html

Goldberg, D. P. (1979). A scaled version of the Goldberg \& Hiller Questionnaire. Psychological Medicine, 9, 139-145.
Hansen, A., Buitendach, J. H., \& Kanengoni, H. (2015). Psychological capital, subjective well-being, burnout and job satisfaction amongst educators in the Umlazi region in South Africa. SA Journal of Human Resource Management, 13(1), a621. [DOI:10.4102/ sajhrm.v13i1.621]

Hashemi, S. E., Savadkouhi, S., Naami, A., \& Beshlideh, K. (2018) Relationship between job stress and workplace incivility regarding to the moderating role of psychological capital. Journal of Fundamentals of Mental Health, 20(2), 103-12. [DOI:10.22038/ JFMH.2018.10407]

Huitt, W. (1988). Personality differences between Navajo and nonIndian college students: Implications for instruction. Equity $\mathcal{E}$ Excellence, 24(1), 71-4.

Jamal, M., \& Baba, V. V. (1992). Shiftwork and department-type related to job stress, work attitudes and behavioral intentions: A study of nurses. Journal of Organizational Behavior, 13(5), 449-64. [DOI:10.1002/job.4030130503]

Jennings, B. M. (2008). Work stress and burnout among nurses: Role of the work environment and working conditions. In R. G. Hughes, (Ed.), Patient safety and quality: An evidence-based handbook for nurses. Rockville, MD: Agency for Healthcare Research and Quality (US). [PMID]

Kan, D., \& Yu, X. (2016). Occupational stress, work-family conflict and depressive symptoms among Chinese bank employees: The role of psychological capital. International Journal of Environmental Research and Public Health, 13(1), 134. [DOI:10.3390/ ijerph13010134]

Kelly, M., Soles, R., Garcia, E., \& Kundu, I. (2020). Job stress, burnout, work-life balance, well-being, and job satisfaction among pathology residents and fellows. American Journal of Clinical Pathology, 153(4), 449-69. [DOI:10.1093/ajcp/aqaa013] [PMID]

Khamisa, N., Peltzer, K., Ilic, D., \& Oldenburg, B. (2017). Effect of personal and work stress on burnout, job satisfaction and general health of hospital nurses in South Africa. Health SA Gesondheid, 22, a1011. [DOI:10.1016/j.hsag.2016.10.001]

Krasikova, D. V., Lester, P. B. \& Harms, P. D. (2015). Effects of psychological capital on mental health and substance abuse Journal of Leadership \& Organizational Studies, 22(3), 280-91. [DOI:10.1177/1548051815585853]

Leon-Perez, J. M., Antino, M., Leon-Rubio, J. M. (2016). The role of psychological capital and intragroup conflict on employees burnout and quality of service: A multilevel approach. Frontiers in Psychology, 7, 1755. [DOI:10.3389/fpsyg.2016.01755] [PMID] [PMCID]

Li, X., Kan, D., Liu, L., Shi, M., Wang, Y., \& Yang, X., et al. (2015) The mediating role of psychological capital on the association between occupational stress and job burnout among bank employees in China. International Journal of Environmental Research and Public Health, 12(3), 2984-3001. [DOI:10.3390/ijerph120302984] [PMID] [PMCID]

Lizano, E. L., \& Barak, M. M. (2015). Job burnout and affective wellbeing: A longitudinal study of burnout and job satisfaction among public child welfare workers. Children and Youth Services Review, 55, 18-28.

Luthans, F., Youssef, C. M., \& Avolio, B. J. (2007). Psychological capital: Investing and developing positive organizational behavior Positive organizational Behavior, 1(2), 9-24. 
Luthans, F., \& Youssef, C. M. (2007). Emerging positive organizational behavior. Journal of Management, 33(3), 321-49. [DOI:10.1177/0149206307300814]

Luthans, F., Avey, J. B., \& Patera, J. L. (2008). Experimental analysis of a web-based training intervention to develop positive psychological capital. Academy of Management Learning \& Education, 7(2), 209-21. [DOI:10.5465/amle.2008.32712618]

Luthans, F., Avolio, B. J., Avey, J. B., \& Norman, S. M. (2007). Positive psychological capital: Measurement and relationship with performance and satisfaction. Personnel Psychology, 60(3), 541-72. [DOI:10.1111/ j.1744-6570.2007.00083.x]

Luthans, F., Youssef, C. M., \& Avolio, B. J. (2007). Psychological capital: Developing the human competitive edge. Oxford: Oxford University Press. [DOI:10.1093/acprof:oso/9780195187526.001.0001]

Luthans, F., Youssef, C. M., Sweetman, D. S., \& Harms, P. D. (2013). Meeting the leadership challenge of employee wellbeing through relationship PsyCap and health PsyCap. Journal of Leadership \& Organizational Studies, 20(1), 118-33. [DOI:10.1177/1548051812465893]

Maslach, C., Jackson, S. E., \& Leiter, M. P. (1996). Maslach burnout inventory manual. Palo Alto, CA: Consulting Psychologists Press. https:/ / books.google.com/books?id=hhgvNQAACAAJ\&dq

Maslach, C., \& Jackson, S. E. (1981). The measurement of experienced burnout. Journal of Organizational Behavior, 2(2), 99-113.

Masten, A. S., \& Reed, M. G. J. (2002). Resilience in development. In C. R. Snyder \& S. J. Lopez, (Eds.), Handbook of positive psychology (pp. 74-88). New York: Oxford University Press. https://books. google.com/books?id=2Cr5rP8jOnsC\&dq

Matoori, H. H. (2017). [Investigating the relationship between psychological capital and perceived organizational support with work engagement among nurses (Persian)]. Iranian Journal of Psychiatric Nursing, 5(2), 45-51. [DOI:10.21859/ijpn-05027]

Mehrabizadeh Honarmand, M., Atashafrouz, A., Shehni Yiylagh M., \& Rezaie, Sh. (2014). [Comparison of general health, job stress, and burnout among ordinary and mental-retarded-student schools' teachers (Persian)]. Clinical Psychology \& Personality, 2(9), 53-64. http://cpap.shahed.ac.ir/article-1-435-en.html

Nezami, A., \& Givarian, H. (2016). [An investigation of the effect of psychological capital on the burnout of nurses in a military hospital in Tehran (Persian)]. EBNESINA, 18(1), 44-51. http:// ebnesina.ajaums.ac.ir/article-1-393-en.html

Peng, J., Jiang, X., Zhang, J., Xiao, R., Song, Y., \& Feng, X., et al. (2013). The impact of psychological capital on job burnout of Chinese nurses: The mediator role of organizational commitment. PLoS One, 8(12), e84193. [DOI:10.1371/journal.pone.0084193] [PMID] [PMCID]

Peterson, S. J., \& Zhang, Z. (2011). Examining the relationships between top management team psychological characteristics, transformational leadership, and business unit performance. In M. A. Carpenter, (Ed.), The handbook of research on top management teams (pp. 127-149). Cheltenham: Edward Elgar Publishing. [DOI:10.4337/97808579 33201.00013]

Rabenu, E., Yaniv, E., \& Elizur, D. (2017). The relationship between psychological capital, coping with stress, well-being, and performance. Current Psychology, 36(4), 875-87. [DOI:10.1007/s12144016-9477-4]
Seligman, M. E. P. (1998). Learned optimism. New York City: Pocket Books. https://books.google.com/books?id=sHVMKaXeg8C\&dq

Selvaraj, P. R., \& Bhat, C. S. (2018). Predicting the mental health of college students with psychological capital. Journal of Mental Health, 27(3), 279-87. [DOI:10.1080/09638237.2018.1469738] [PMID]

Selye, H. (1976). The stress concept. Canadian Medical Association Journal, 115(8), 718.

Spooner-Lane, R. (2004). The influence of work stress and work support on burnout in public hospital nurses [PhD. thesis]. Brisbane City: Queensland University of Technology. https://eprints.qut.edu. au/15975/

Story, J. S. P., Youssef, C. M., Luthans, F., Barbuto, J. E., \& Bovaird J. (2013). Contagion effect of global leaders' positive psychological capital on followers: Does distance and quality of relationship matter? The International Journal of Human Resource Management 24(13), 2534-53. [DOI:10.1080/09585192.2012.744338]

Sugawara, N., Danjo, K., Furukori, H., Sato, Y., Tomita, T., \& Fujii, A., et al. (2017). Work-family conflict as a mediator between occupational stress and psychological health among mental health nurses in Japan. Neuropsychiatric Disease and Treatment, 13, 779-84. [DOI:10.2147/NDT.S127053] [PMID] [PMCID]

Tang, J. J. (2020). Psychological capital and entrepreneurship sustainability. Frontiers in Psychology, 11, 866. [DOI:10.3389/fpsyg.2020.00866] [PMID] [PMCID]

Thuynsma, C., \& de Beer, L. T. (2017). Burnout, depressive symptoms, job demands and satisfaction with life: Discriminant validity and explained variance. South African Journal of Psychology, 47(1), 46-59. [DOI:10.1177/0081246316638564]

Toker, Sh., Melamed, S., Berliner, Sh., Zeltser, D., \& Shapira, I. (2012). Burnout and risk of coronary heart disease: A prospective study of 8838 employees. Psychosomatic Medicine, 74(8), 840-7. [DOI:10.1097/PSY.0b013e31826c3174] [PMID]

Wang, Z., Liu, H., Yu, H., Wu, Y., Chang, Sh., \& Wang, L. (2017). Associations between occupational stress, burnout and well-being among manufacturing workers: Mediating roles of psychological capital and self-esteem. BMC Psychiatry, 17(1), 364. [DOI:10.1186/ s12888-017-1533-6] [PMID] [PMCID]

Yim, H. Y., Seo, H. J., Cho, Y., \& Kim, J. H. (2017). Mediating role of psychological capital in relationship between occupational stress and turnover intention among nurses at veterans administration hospitals in Korea. Asian Nursing Research, 11(1), 6-12. [DOI:10.1016/j.anr.2017.01.002] [PMID]

Yoshizawa, K., Sugawara, N., Yasui-Furukori, N., Danjo, K., Furukori, H., \& Sato, Y., et al. (2016). Relationship between occupational stress and depression among psychiatric nurses in Japan. Archives of Environmental \& Occupational Health, 71(1), 10-5. [DOI 10.1080/19338244.2014.927345] [PMID]

Youssef-Morgan, C. M., \& Luthans, F. (2013). Psychological capital theory: Toward a positive holistic model. In A. B. Bakker (Ed.), Advances in positive organizational psychology (pp. 145-166). Vol. 1. Bingley: Emerald Group Publishing Limited. [DOI:10.1108/ S2046-410X(2013)0000001009] 
This Page Intentionally Left Blank 